\title{
Can affordability and innovation coexist for medicines?
}

\author{
Improved transparency is essential to determine what is fair
}

\author{
Allison Colbert, technical officer \\ Andrew Rintoul, scientist \\ Mariângela Simão, assistant director general \\ Suzanne Hill, director \\ Soumya Swaminathan, chief scientist \\ World Health Organization, Geneva, Switzerland \\ Correspondence to: A Colbert \\ colberta@who.int
}

A worrying gap exists between the promise of medical innovation and affordable access for all. When medicines are found to be truly effective they must be made rapidly available to both health systems and the individuals who need them at an affordable price.

Sadly, some effective medicines remain unavailable to many patients or are available with out-of-pocket costs that make access impossible. In many low income countries the cost of treatment for diseases such as cancer can be devastating because it is the full financial responsibility of the patient. ${ }^{1}$ When a potential cure for hepatitis $\mathrm{C}$ recently became available even high income countries found themselves rationing treatment and unable to treat all patients in need because of high prices. ${ }^{2}$ These examples are unacceptable.

There are still no treatments available for many public health problems yet drug development pipelines are full for potentially profitable diseases that mainly affect high income countries. In short, the free market simply does not work to effectively provide affordable access to medicines for all.

Where there are limited markets and incentives to develop drugs for neglected diseases and populations there is a pressing need for better coordination. To this end the World Health Organization (WHO) has recently launched an online resource to guide the development of new health products by providing a searchable database of key characteristics of desired medicines, vaccines, diagnostics, and medical equipment. ${ }^{3}$

\section{Defining fair pricing}

WHO also convenes a series of meetings to bring together stakeholders to discuss options for a fairer pricing system. Central to the concept of fair pricing is striking a balance between the public health needs for innovation and affordability, while recognising that quality health products are imperative and that sustainable production comes at a cost.

This week sees the publication of a collection of articles in The BMJ that outlines evidence and further research that is needed to balance affordability and innovation (www.bmj.com/fair-pricing). We believe that affordability and innovation can coexist so that patients can sustainably access medicines. However, the articles show that it is challenging to find agreement on a single definition of fair pricing, and health systems have struggled to achieve a balance between affordability and need.

Transparency is a key element to determine what is fair, but there is an absence of reliable data on development costs. Without data it is difficult to accept the argument that the costs of development, even accounting for failed research, make high prices for new medicines inevitable. Innovations can and should lead to financial returns for those investing in research, but this should not eclipse the societal benefits of a new medicine.

Transparency around development costs will also shed light on the substantial role of the public sector in funding research and development. This will ensure the public does not pay twice and receives a public return on public investments.

Product development is a risky investment, with long lead times, uncertain scientific outcomes, and changing political environments, which all affect future sales forecasts. However, responding to uncertainty by restricting access through market monopolies and charging high prices is not an acceptable solution. We need to develop mechanisms to reduce prices and increase volumes; this could benefit all stakeholders.

Governments agreed to move towards improving the transparency of markets for health products at the 2019 World Health Assembly. ${ }^{4}$ The resolution aims to enhance public sharing of information on actual prices paid by governments and other buyers for health products, and greater transparency on pharmaceutical patents, clinical trial results, and other determinants of pricing along the value chain from laboratory to patient. It also requests the WHO secretariat to support efforts towards transparency and monitor the effect of transparency on affordability and availability of health products.

Ultimately, there is no simple algorithm that will calculate a fair price for each medicine. However, transparency could ensure that the right data are available to the right stakeholders so that practical solutions guaranteeing affordable access to medicines can be implemented. This will require collaboration to build upon what fairness means in practice so that stakeholders can work together to achieve it.

Competing interests:We have read and understood BMJ policy on declaration of interests and have no relevant interests to declare. The views expressed in this editorial do not necessarily reflect those of WHO.

Provenance and peer review: Commissioned; not externally peer reviewed.

This article is part of a series proposed by WHO and commissioned by The BMJ. The BMJ retained full editorial control over external peer review, editing, and publication of these articles. Open access fees are funded by WHO.

\section{(@) $(1 \otimes)$ OPEN ACCESS}

This is an Open Access article distributed under the terms of the Creative Commons Attribution IGO License (https://creativecommons.org/licenses/by-nc/3.0/ igo/), which permits use, distribution, and reproduction for non-commercial purposes in any medium, provided the original work is properly cited.

\section{Check for updates}

World Health Organization. Technical report: pricing of cancer medicines and its impacts: a comprehensive technical report for the World Health Assembly Resolution 70.12: operative paragraph 2.9 on pricing approaches and their impacts on availability and affordability of medicines for the prevention and treatment of cancer. World Health Organization, 2018.

2 lyengar S, Tay-Teo K, Vogler S, et al. Prices, costs, and affordability of new medicines for hepatitis $C$ in 30 countries: an economic analysis. PLoS Med 2016;13:e1002032. doi:10.1371/journal. pmed.1002032

3 TDR. Health product profile directory. https://www.who. int/tdr/diseases-topics/product-directory/en/

4 World Health Organization. Resolution WHA 72.8: Improving the transparency of markets for medicines, vaccines, and other health products. 2019. https:// apps.who.int/gb/ebwha/pdf_files/WHA72/A72_ ACONF2Rev1-en.pdf

Cite this as: BMJ 2020;368:17058 http://dx.doi.org/10.1136/bmj.17058 